transferred to my care, the bullet had passed through the back of the orbit, and directly injured the posterior part of the globe. There were chemosis, proptosis, much ecchymosis in lids and conjunctiva, and some intra-ocular hæmorrhage. The proptosis and chemosis subsided. The eye did not inflame. Its tension became minus. It had, of course, no sight, but the man was able to go home with the eye in, although cosmetically not perfect, and somewhat shrunken. He was advised to have it removed later.

(c) Another bullet took an extraordinary course.-It pierced the right upper lid in its external third, passed out between the edges of the lids without wounding them, but after destroying the cornea, and indirectly the lens, pierced the skin again where the lower lid joined the cheek, passed through the right nostril and the floor of the left nostril, and out through the upper lip below the left nostril. The right eye was removed on admission.

4. Traumatic myopia.-A soldier on the island injured his right eye while chopping wood. The lens was dislocated forward, making the anterior chamber shallow, and causing five dioptres of myopia in a previously emmetropic eye. The lens remained clear, and with -5D. the eye saw 6/12. As I have observed twice before, complete accommodation was retained, although the ciliary muscle must have been ruptured.

5. Post-diphtheritic paralysis.-Swabs from the nasopharynges of two cases of paralysis of accommodation enabled both to be pronounced by the pathologist to be diphtheria carriers. The previous slight sore throats had not called for treatment in camp.

\title{
FUNDUS LESIONS IN CASES OF WAR NEPHRITIS*
}

\section{BY \\ J. JAMESON EVANS, BIRMINGHAM.}

THE Medical Research Committee is investigating selected cases of war nephritis, and among other particulars concerning which information is desired, is the state of the fundus oculi. In the course of my examination of these cases at the First and Second Birmingham War Hospitals I found certain fundus changes which suggested to me that if ophthalmoscopic investigations were to be of any help to the Committee, we should have to examine every case of war nephritis, and the results obtained by different observers should be then examined in order, if possible, to decide whether this particular form of nephritis causes, or is associated with, changes in

\footnotetext{
*Communicated to the 1917 Congress of the Ophthalmological Society of the United Kingdom. The full article will be published in the Society's Transactions.
} 
the fundus; how far these changes may be regarded as of renal origin; and whether they can be looked upon as of any diagnostic or prognostic significance.

I should like to mention that, so far as my experience goes, the fundus changes which are likely to be met with are very slight in degree and may easily be overlooked unless the examination be made after dilatation of the pupil by direct ophthalmoscopy. Another point I should like to emphasize is that I do not wish to imply that these changes are the result of trench or war nephritis - that can only be decided when we have collected reports from all the investigators - and they must only.be accepted as lesions which have been observed in cases which have been diagnosed for me as war nephritis. Further, no attempt has been made to differentiate types or degrees of nephritis, but I think that in future some effort should be made in this direction, but this, again, would have to be done through the Research Committee and the officers in charge of the cases. The following is the result of my examination of the fundus in 100 cases of war nephritis :-

Normal fundus $\quad \ldots \quad \ldots \quad 43$ per cent.

Changes noted in the fundus ... 57 , ,

The fundus changes observed:

1. Involved the optic nerve and retina in 39 cases.

2. Involved the choroid , 34 ,"

1. Lesions of the optic nerve and retina.-These were in the main very insignificant, and some were so slight in degree that they were doubtfully pathological. In twenty-two cases the optic disc was hyperæmic and slightly œdematous; in thirteen cases there was peripapillary retinal œdema, some perivascular lining, and tortuosity and fulness of the veins. In eight cases the disc appeared pale or greyish without any definite atrophy of the papilla. In only one case was the classical appearance of the hæmorrhagic neuro-retinitis of albuminuria observed, and this was in a man who was fifty-six years of age, and who evidently suffered from chronic Bright's disease. In no other case were retinal hæmorrhages observed. In no other case was any definite evidence of arterio-sclerosis noted, although in two cases there was some suspicion of arterial pressure on the veins. Fine dotted changes in the retina in the macular region were observed in four cases, and one case showed some œdema at the macula with reduction of vision to $6 / 24 .{ }^{*}$

2. Changes in the choroid.-I was rather surprised to find so many cases showing evidence of choroidal disturbances. Here, again, doubts could be entertained as to their pathological character. Yarticularly does this apply to eighteen cases which showed

${ }^{*}$ The discrepancy in the figures is to be explained by over lapping of the conditions.EDITOR. 
depigmentary changes in the equatorial region. These depigmented areas were sometimes arranged diffusedly around the periphery and often showed fine pigmentary deposits; or they were confined to a sector of the globe. At other times they appeared as whitish or yellowish streaks with slightly pigmented borders, reaching from the intermediate zone to the periphery. In none of these cases was there any evidence that there had been acute choroiditis. In twelve cases, however, there were discrete orange coloured spots with little or no pigmentation but evidently of the type of disseminated choroiditis. Two cases showed typical areolar choroiditis with marked pigmentation, such as one might ascribe to syphilis.

Five cases showed guttate changes in the macular region and these we should at once diagnose in patients of more advanced age as central guttate choroiditis, or Tay's choroiditis.

The most peculiar choroidal changes observed were patches of slaty discolouration in the neighbourhood of the macula. These spots-only one of which was larger in size than the optic discappeared to be slightly raised and the retina over them gave a sheeny reflex. There were five such cases. In three the spots were situated along the inferior temporal vessels, in one along the superior temporal, and in one on the outer edge of the macula. They seemed to be deeply situated, and only in the last case was vision affected, and it is doubtful if even in this case the depreciation could be ascribed to the slaty spot, as the vision was the same in the unaffected eye (6/12). It may here be remarked that except where the macula was odematous, there was no reduction of vision, and in no case was I asked to examine a patient because of his sight.

As to the character of the lesion, it would appear that both in the retina and the choroid the process is of a low inflammatory nature, giving rise, on the one hand, to slight œdema of the papilla and neighbouring retina, and occasionally a few fine retinal deposits; on the other, setting up depigmentary changes in the hexagonal epithelium and choroid, either with or without slight and fine pigmentary deposits; and occasionally more acute, but more localized foci, showing as fine areolar spots with very limited pigmentary deposits at their edges. The more definitely punched-out yellow or white spots with markedly pigmented rims have been ascribed to syphilis.

The slaty patches are suggestive of small choroidal hæmorrhages; but I can hardly believe they are of that nature, seeing that no hæmorrhages were observed in the retina, and there was no evidence of choroidal congestion. It is possible they were due to small choroidal thromboses.

The nature of the poison.-The changes observed seem to point to a toxic or infective origin. They approach in the main the 
fundus lesions we associate with toxicity of advancing age or senility. Diffuse depigmentary changes I have also observed in children, and have ascribed them to the autotoxæmia of gastroenteritis and such internal disturbances as infants are prone to. The nephritis is of the type which follows scarlet fever, and it is possible that the changes are produced by an infective element. It is also possible that fundus lesions are not uncommon in scarlatinal nephritis, but few of us have had the occasion to examine many cases of the kind. Syphilis has been suggested as the cause, but except in the two exceptional cases referred to above, the appearances of the fundus changes were not, to me, suggestive of syphilis. Sepsis, particularly oral sepsis, has also been suggested as a cause of the nephritis; but there is nothing in the fundus lesions, any more than in the epidemiological aspects of the disease, that gives any support to such a suggestion.

\title{
A CASE OF ETHMOIDAL INJURY ASSOCIATED WITH PAPILLEDEMA, ABDUCENS PALSY, AND OTHER OCULAR LESIONS
}

\author{
BY
}

Captain F. W. Watkyn-Thomas, B.C.Cantab., R.A.M.C. (T.C.) AND

CAPTAIN R. L. ScotT, F.R.C.S.Edin., R.A.M.C. (T.C.)

FROM A BASE HOSPITAL IN FRANCE.

PAPILLCEDEMA and other affections of the eye have frequently been observed in cases of accessory sinus suppuration, more especially when the suppuration has been in the sphenoidal or posterior ethmoidal cells. The structural features have been fully described by Onodi, Loeb, and others.

The following case presents some points of interest :-

$\mathrm{N}$ - , a powerfully-built countryman, aged twenty-four, is a lance-corporal in a tunnelling company, with thirty months' service. There is no previous history of any ocular trouble except for a "black eye" (right) following a blow from a cricket ball three months previously. He is certain that he had quite recovered from this before he was wounded. On March 28, 1917, he was struck below the right eye by a fragment of 'shell; earlier in the day he had received a very slight bayonet wound in the right arm. There was no definite history of concussion, and he remembers being carried to the advanced dressing station.

The sight of the right eye has been dim from that time. The wound of the arm was excised, and the face wound, a small 